\title{
Customers' Attitudinal, Emotional and Behavioural Responses to Firm-Initiated Service Termination: An Abstract
}

\author{
Amin Nazifi and Dahlia El-Manstrly
}

\begin{abstract}
There are an increasing number of reports on termination of customer relationships initiated by major banks in the press. Yet, our understanding of the negative consequences of firm-initiated service termination is still very limited. This study looks at two distinct termination strategies (firm-oriented and customeroriented) to compare how customers perceive and react to these termination strategies. In particular, we examine how perceived severity of the two strategies affects customers' distributive justice, anger, customers' complaint behaviour and revenge intentions. We also explore the mediating role of distributive justice and anger as well as the moderating role of attitude towards complaining. We use an experiment in a retail banking context. 746 adult consumers were recruited from a US online panel with quota for age and gender. Our results show that a firm-oriented approach is perceived as more severe and less fair compared with a customer-oriented approach. A firm-oriented approach also leads to higher level of anger, complaint behaviour and revenge intentions. We also find support for the mediating role of anger and distributive justice on the severity behavioural responses' links and also the moderating role of attitude towards complaining on the effects of anger on revenge and third-party complaint behaviours. This study contributes to the service termination literature by providing a comprehensive model of disengaged customers' attitudinal, emotional and behavioural reactions to firm-initiated service termination.
\end{abstract}

References Available Upon Request

\author{
A. Nazifi $(\bowtie) \cdot$ D. El-Manstrly \\ University of Edinburgh, Edinburgh, UK \\ e-mail: amin.nazifi@ed.ac.uk; dahlia.el-manstrly@ed.ac.uk
}

